\title{
Sub-exact sequence of rough groups
}

\author{
Nevi Setyaningsih ${ }^{1}$, Fitriani ${ }^{*}$, Ahmad Faisol ${ }^{1}$ \\ ${ }^{1}$ Universitas Lampung, Indonesia \\ $\triangle$ fitriani.1984@fmipa.unila.ac.id*
}

Article Information

Submitted May 05, 2021

Revised August, 122021

Accepted August 15, 2021

\section{Keywords}

Exact Sequence;

Sub-exact Sequence;

Group;

Rough Set.

\section{Abstract}

Rough Set Theory (RST) is an essential mathematical tool to deal with imprecise, inconsistent, incomplete information and knowledge Rough Some algebra structures, such as groups, rings, and modules, have been presented on rough set theory. The sub-exact sequence is a generalization of the exact sequence. In this paper, we introduce the notion of a sub-exact sequence of groups. Furthermore, we give some properties of the rough group and rough sub-exact sequence of groups.

\section{INTRODUCTION}

Pawlak first introduced the rough set theory in 1982 (Pawlak, 1991). This is an advanced theory of set theory, in which the subsets of the universal set are explained by a tuple of lower approximations and upper approximations. The basic concept of a rough set is the equivalence relation.

Let $U$ is a finite non-empty set called universal set, and $\theta$ is an equivalence relation in $U$. The tuple $(U, \theta)$ is called the approximation space (Miao et al., 2005). The lower approximation of a set is a combination of all equivalence classes, the smallest subset. The upper approximation of a set $X$, denote by $\operatorname{Apr}(X)$, combines all equivalence classes with the largest set. A tuple $(A, B) \in P(U) \times P(U)$ is called a rough set in $(U, \theta)$ if $(A, B)=A p r(X)$ for $X \in P(U)$, where $P(U)$ is the power set of $(U)$ and $\operatorname{Apr}(X)$ is the approximation of $X$.

In 1994, Biswas and Nanda (Biswas \& Nanda, 1994) introduced the rough subgroup. Furthermore, Kuroki (Kuroki, 1997) introduced the idea of rough ideals in semigroups in 1997. In 2001, Han Suqing (Miao et al., 2005) investigated homomorphism and isomorphism on rough set. Subsequently, Davvaz (2004) studied the relationship between the rough set and the ring theory by considering the ring as a universal set and introducing the abstraction ideal notation and the abstraction subring concerning the ideal of a ring. In 2006, Davvaz and Mahdavipour (Davvaz \& Mahdavipour, 2006) investigated the rough module. Furthermore, rough semigroups on approximation space (Bagirmaz \& Ozcan, 2015), homomorphism of rough groups (Jesmalar, 2017), rough G-modules (Isaac \& Paul, 2017), and direct products of rough subgroups (Bagirmaz, 2019) are investigated. Besides that, Sinha and Prakash (Sinha \& Prakash, 2016) studied the exact sequence of the rough module. They define the exact sequence of rough modules on the rough ring $\operatorname{Apr}(R)$.

Let $R$ be a ring and let $A \stackrel{f}{\rightarrow} B \stackrel{g}{\rightarrow} C$ is the exact sequence over $R$-module such that $\operatorname{Im} f=$ Ker $g\left(=g^{-1}(0)\right)$. Davvaz \& Parnian-Garamaleky (1999) introduced the concept of $U$-exact by replacing 0 with sub-module $U \subseteq C$. Motivated by Davvaz and Parnian-Garamaleky, who introduced the $U$-exact sequence concept. In 2016, Fitriani et al. gave new ideas from generalizing exact sequences to the $X$-sub-exact sequence of modules by replacing R-module 
$B$ with arbitrary submodule $X$ of $B$ (Fitriani et al., 2016). Besides that, motivated by the U-exact sequence, Elfiyanti et al. give an Abelian property of the category of U-complexes (Elfiyanti et al., 2016). In 2017, Aminizadeh et al. (2018) introduced quasi exact sequence of S-acts. Furthermore, Fitriani et al. gave an X-sub-linearly independent module a new concept (Fitriani et al., 2017). In 2018, they introduced a U-generated module (Fitriani et al., 2018b). Furthermore, they established $U$-basis and $U$-free modules by using the concept of a sub-exact sequence of modules (Fitriani et al., 2018a). In addition, the sub-exact sequences can be used to determine the Noetherian property of the submodule of the generalized power series module (Faisol et al., 2021).

Let $U^{\prime}, U, U^{\prime \prime}$ be $R$-modules and $X$ be a submodule of $U$. The triple ( $\left.U^{\prime}, U, U^{\prime}\right)$ is said to be an $X$-sub-exact on $U$ if there is $R$-homomorphisms $f$ and $g$ so the sequence of $R$-modules $U^{\prime}$ $\stackrel{f}{\rightarrow} U \stackrel{g}{\rightarrow} U^{\prime \prime}$ is exact. The set of all submodule $X$ in $L$ such that the sequence $U^{\prime} \stackrel{f}{\rightarrow} U \stackrel{g}{\rightarrow} U^{\prime \prime}$ is exact, is denoted by $\sigma\left(U^{\prime}, U, U^{\prime \prime}\right)$.

Based on the definition of sub-exact sequence, we introduce the notion of a sub-exact sequence of rough groups in this paper. Furthermore, we give some properties of the rough group and sub-exact sequence of rough groups. These properties can be used to determine all submodules $\mathrm{X}$ in $U$ so that the triple $\left(U^{\prime}, U, U^{\prime \prime}\right)$ is rough $X$-sub-exact.

\section{METHODS}

The research methods are based on literature, especially those related to the standard set, the upper and lower approximations space, the rough group, the exact sequence, and the sub-exact sequence. Our research steps are as follows. First, we define the rough sub-exact sequences of rough groups. Furthermore, we investigate the properties of the rough group and construct the example of the rough sub-exact sequence of groups using the finite set. Finally, we investigate the properties of the rough sub-exact sequences of rough groups.

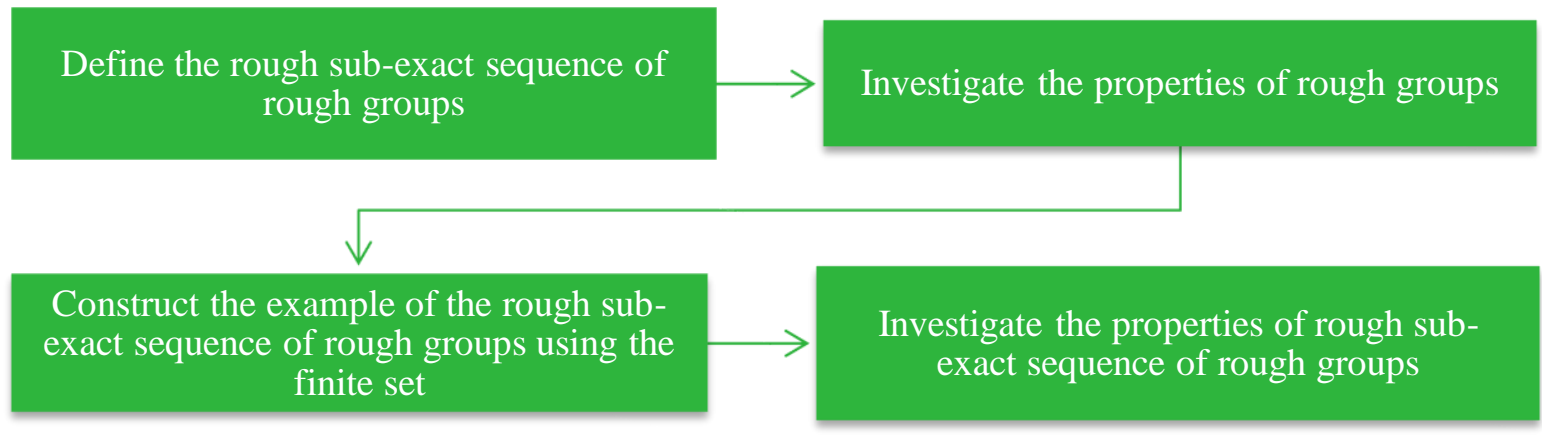

Figure 1. Research stage diagram

\section{RESULTS AND DISCUSSION}

Before we construct the rough sub-exact of groups, we recall the definition of rough group, subexact sequence, and exact sequence of the rough module over the rough ring as follows.

Definition 1. (Miao et al., 2005) Let $K=(U, R)$ be an approximation space and $*$ be a binary operation defined on $U$. A subset $G(G \neq \varnothing)$ of universe $U$ is called a rough group if $\operatorname{Apr}(G)=$ $(\underline{A p r}(G), \overline{A p r}(G))$ the following properties are satisfied:

(1) for every $x * y \in \overline{A p r}(G), x * y \in G$;

(2) association property holds in $\overline{A p r}(G)$; 
(3) there exists $e \in \overline{A p r}(G)$ such that $x \in G, x * e=e * x=x$; $e$ is called the rough identity element of rough group $G$;

(4) for every $x \in G$, there exists $y \in G$, such that $x * y=y * x=e$; $y$ is called the rough inverse element of $x$ in $G$.

Definition 2. (Fitriani et al., 2016) Let $K, L, M$ be R-modules and $X$ be a submodule of $L$. Then the triple $(K, L, M)$ is said to be $X$-sub-exact at $L$ if there exist $R$-homomorphisms $f$ and $g$ such that the sequence of $R$-modules and $R$-homomorphisms $K \stackrel{f}{\rightarrow} X \stackrel{g}{\rightarrow} M$ is exact.

Definition 3. (Sinha \& Prakash, 2016) A sequence $\operatorname{Apr}\left(M^{\prime}\right) \stackrel{f}{\rightarrow} \operatorname{Apr}(M) \stackrel{g}{\rightarrow} \operatorname{Apr}\left(M^{\prime \prime}\right)$ of two homomorphism of a module over the ring $(R)$ is said to be rough exact if $\operatorname{Im} f=\operatorname{Ker} g$. This happens if and only if $g f=0$, and the relation $g(x)=0, x \in \operatorname{Apr}(M)$, implies that $x=f\left(x^{\prime}\right)$ for some $x^{\prime} \in \operatorname{Apr}\left(M^{\prime}\right)$.

Based on the definition of the sub-exact sequence of modules, we define the exact sequence of rough groups as follows.

Definition 4. Let $U^{\prime}, U, U^{\prime \prime}$ be rough groups, and $X$ be a rough subgroup of $U$. Then the triple $\left(U^{\prime}, U, U^{\prime \prime}\right)$ is said to be rough $X$-sub-exact at $U$ if there exist rough homomorphisms $f$ and $g$ such that the sequence of rough groups and rough group homomorphisms:

is exact.

$$
\operatorname{Apr}\left(U^{\prime}\right) \stackrel{f}{\rightarrow} \operatorname{Apr}(U) \stackrel{g}{\rightarrow} \operatorname{Apr}\left(U^{\prime \prime}\right)
$$

Based on Definition 4, every rough exact sequence is a rough sub-exact sequence of groups. However, the converse need not be true. Therefore, before we give the properties of a rough sub-exact sequence, we provide the properties of the rough group as follows.

Proposition 5. Let $(U, \theta)$ be an approximation space, and let $X_{1}, X_{2}$ be subsets of $U$. If $X_{1}$ and $X_{2}$ are rough groups with $\overline{A p r}\left(X_{1}\right)=\overline{A p r}\left(X_{2}\right)$, then $X_{1} \cup X_{2}$ is also the rough group.

Proof. Let $*$ be a binary operation defined on $U$. It is clear that $\overline{A p r}\left(X_{1} \cup X_{2}\right)=\overline{A p r}\left(X_{1}\right) \cup$ $\overline{A p r}\left(X_{2}\right)$. By assumption, $\overline{A p r}\left(X_{1}\right)=\overline{A p r}\left(X_{2}\right)$. Let $a \in \overline{A p r}\left(X_{1} \cup X_{2}\right)$ and $b \in \overline{A p r}\left(X_{1} \cup\right.$ $\left.X_{2}\right)$. Then $a \in \overline{A p r}\left(X_{1}\right)$ and $b \in \overline{A p r}\left(X_{1}\right)$. Since $X_{1}$ is the rough group, we have $a * b \in$ $\overline{A p r}\left(X_{1}\right)$. Hence $a * b \in \overline{A p r}\left(X_{1} \cup X_{2}\right)$. For every $a, b, c \in X_{1} \cup X_{2}$, the associative property holds in $\overline{A p r}\left(X_{1} \cup X_{2}\right)$, i.e., $a *(b * c)=(a * b) * c$. Since $X_{1}$ is a rough group, we have the identity element $e \in \overline{A p r}\left(X_{1}\right)=\overline{A p r}\left(X_{1} \cup X_{2}\right)$. Finally, we want to show that every element in $\overline{A p r}\left(X_{1} \cup X_{2}\right)$ has an inverse. By assumption, $\overline{A p r}\left(X_{1}\right)=\overline{A p r}\left(X_{2}\right)$, so that $\overline{A p r}\left(X_{1} \cup X_{2}\right)=\overline{A p r}\left(X_{1}\right)$. This implies that every element in the set $X_{1} \cup X_{2}$ has an inverse in $\overline{A p r}\left(X_{1} \cup X_{2}\right)$. Therefore, it proved $\left(X_{1} \cup X_{2}\right)$ is a rough group.

By applying Proposition 5 to a finite number of subsets $U$, we have the following property of the rough group.

Corollary 6. Let $(U, \theta)$ be an approximation space, and let $X_{1}, X_{2}, \ldots X_{\mathrm{n}}$ be subsets of $U$. If $X_{1}, X_{2}, \ldots, X_{\mathrm{n}}$ are rough groups with $\overline{\operatorname{Apr}}\left(X_{1}\right)=\overline{\operatorname{Apr}}\left(X_{2}\right)=\cdots=\overline{\operatorname{Apr}}\left(X_{\mathrm{n}}\right)$, then $\bigcup_{i=1}^{n} X_{\mathrm{i}}$ is also the rough group. 
Example 1. Let $U=\{0,1,2,3,4, \ldots, 149\}$. We define the relation $\theta$ in $U$, where $u \theta v$ if and only if $u-v=13 k$, for some $k \in \mathbb{Z}$. It is easy to show that $\theta$ is an equivalence relation on $U$. From this equivalence relation, we have 13 equivalence classes as described in the following table.

Table 1. The Equivalence Classes of $U$

\begin{tabular}{lcl}
\hline No & The Equivalence Class & The Elements \\
\hline 1 & $E_{1}=[1]$ & $\{1,14,27,40,53,66,79,92,105,118,131,144\}$ \\
2 & $E_{2}=[2]$ & $\{2,15,28,41,54,67,80,93,106,119,132,145\}$ \\
3 & $E_{3}=[3]$ & $\{3,16,29,42,55,68,81,94,107,120,133,146\}$ \\
4 & $E_{4}=[4]$ & $\{4,17,30,43,56,69,82,95,108,121,134,147\}$ \\
5 & $E_{5}=[5]$ & $\{5,18,31,44,57,70,83,96,109,122,135,148\}$ \\
6 & $E_{6}=[6]$ & $\{6,19,32,45,58,71,84,97,110,123,136,149\}$ \\
7 & $E_{7}=[7]$ & $\{7,20,33,46,59,72,85,98,111,124,137\}$ \\
8 & $E_{8}=[8]$ & $\{8,21,34,47,60,73,86,99,112,125,138\}$ \\
9 & $E_{9}=[9]$ & $\{9,22,35,48,61,74,87,100,113,126,139\}$ \\
10 & $E_{10}=[10]$ & $\{10,23,36,49,62,75,88,101,114,127,140\}$ \\
11 & $E_{11}=[11]$ & $\{11,24,37,50,63,76,89,102,115,128,141\}$ \\
12 & $E_{12}=[12]$ & $\{12,25,38,51,64,77,90,103,116,129,142\}$ \\
13 & $E_{13}=[0]$ & $\{0,13,26,39,52,65,78,91,104,117,130,143\}$ \\
\hline
\end{tabular}

The tuple $(U, \theta)$ is an approximate space. Furthermore, we give a subset $X=$ $\{8,9,10,14,28,42,56,70,80,94,108,122,136,140,141,142\} \subseteq U$. Then the lower approximations of $X$ is $\operatorname{Apr}(X)=\emptyset$, and the upper approximations of $X$ is $\overline{A p r}(X)=E_{1} \cup$ $E_{2} \cup E_{3} \cup E_{4} \cup E_{5} \cup E_{6} \cup E_{7} \cup E_{8} \cup E_{9} \cup E_{10} \cup E_{11} \cup E_{12} \cup E_{13}=U$. The rough set $\operatorname{Apr}(X)$ is the ordered pair of the lower and upper approximations written as $\operatorname{Apr}(X)=$ $(\underline{A p r}(X), \overline{A p r}(X))=(\{\},\{0,1,2,3,4,5,6,7,8, \ldots, 147,148,149,149\})$. Next, we define the binary operation $+_{150}$ on rough set $\operatorname{Apr}(X)$. We will show that $X$ is a rough group.

(1) For every $a, b \in X,\left(a+{ }_{150} b\right) \in \overline{A p r}(X)$,

(2) Association property holds in $\overline{A p r}(X)$;

(3) There exists $0 \in \overline{A p r}(X)$ such that for every $x \in X, x+{ }_{150} 0=0+{ }_{150} x=x$.

(4) Table 2 shows that every element in $X$ has an inverse in $\overline{A p r}(X)$.

Table 2. Inverse Element on $X$

\begin{tabular}{lllllllll}
\hline No & 1 & 2 & 3 & 4 & 5 & 6 & 7 & 8 \\
\hline$x \in X$ & 8 & 9 & 10 & 14 & 28 & 42 & 56 & 70 \\
Inverse of $x$ & 142 & 141 & 140 & 136 & 122 & 108 & 94 & 80 \\
\hline
\end{tabular}

It follows from Table 2 that every element of $X$ has an inverse in $\overline{A p r}(X)$. Hence $X$ is a rough group on $U$.

If we take $X_{1}=\{8,9,10,14,28,31,42,56,70,80,94,108,119,122,136,140,141,142\}$, and $X_{2}=\{8,9,10,14,28,42,44,56,70,80,94,106,108,122,136,140,141,142\}$. We can see that every element of $X_{1}$ has invers in $X_{1}$. The same thing happened to the set $X_{2}$. Next, the sets $X_{1}$ and $X_{2}$ satisfy all the properties of rough group. Hence, $X_{1}$ dan $X_{2}$ are rough groups. Furthermore, we will show that $X_{1} \cup X_{2}$ is a rough group in approximation space $(U, \theta)$.

We have $X_{1} \cup X_{2}=\{8,9,10,14,28,31,42,44,56,70,80,94,106,108,119,122,136,140$, $141,142\}$. This implies $\overline{A p r}\left(X_{1} \cup X_{2}\right)=U$. If we take $+_{150}$ as a binary operation in $U$, we get $\left(a+{ }_{150} b\right) \in \overline{A p r}\left(X_{1} \cup X_{2}\right)$, for every $a, b \in X_{1} \cup X_{2}$. Furthermore, the associative property holds in $\overline{A p r}\left(X_{1} \cup X_{2}\right)$. It has an $e \in \overline{A p r}\left(X_{1} \cup X_{2}\right)$ identity element, i.e. $0 \in$ 
$\overline{A p r}\left(X_{1} \cup X_{2}\right)$ so that for each $x \in X_{1} \cup X_{2}, x+{ }_{150} 0=0+{ }_{150} x=x$. Then 0 is an element of identity in $X_{1} \cup X_{2}$. Every element in the $X_{1} \cup X_{2}$ has an inverse in $\overline{A p r}\left(X_{1} \cup X_{2}\right)=U$. So, the set $\left(X_{1} \cup X_{2}\right)$ is a rough group in approximation space $(U, \theta)$. This shows that the union of two rough groups with the same upper approximation is also a rough group.

Next, we will give the properties of the sub-exact sequence of rough groups.

Proposition 7. Let $(U, \theta)$ be an approximation space, and let $X_{1}, X_{2}$ be rough groups of $U$, such that $\overline{\operatorname{Apr}}\left(X_{1}\right)=\overline{\operatorname{Apr}}\left(X_{2}\right)$. The triple $\left(U^{\prime}, U, U^{\prime \prime}\right)$ is a rough $X_{1}$-sub-exact sequence if and only if the triple $\left(U^{\prime}, U, U^{\prime \prime}\right)$ is a rough $X_{2}$-sub-exact sequence.

Proof. We assume that the triple $\left(U^{\prime}, U, U^{\prime \prime}\right)$ is a rough $X_{1}$-sub-exact sequence. Based on Definition 4, the following sequence:

$$
\operatorname{Apr}\left(U^{\prime}\right) \stackrel{f}{\rightarrow} \operatorname{Apr}\left(X_{1}\right) \stackrel{g}{\rightarrow} \operatorname{Apr}\left(U^{\prime \prime}\right)
$$

is rough exact. It implies $\operatorname{Im}(f)=\operatorname{Ker}(g)$, where $f$ is a rough homomorphism from $\operatorname{Apr}\left(U^{\prime}\right)$ to $\operatorname{Apr}\left(X_{1}\right)$, and $g$ is a rough homomorphism from $\operatorname{Apr}\left(X_{1}\right)$ to $\operatorname{Apr}\left(U^{\prime \prime}\right)$. The rough homomorphism $f$ maps every element of $\overline{A p r}\left(\mathrm{U}^{\prime}\right)$ to $\overline{A p r}\left(X_{1}\right)$, and the rough homomorphism $g$ maps every element of $\overline{\operatorname{Apr}}\left(X_{1}\right)$ to $\operatorname{Apr}\left(U^{\prime \prime}\right)$. By hypothesis, $\overline{\operatorname{Apr}}\left(X_{1}\right)=\overline{\operatorname{Apr}}\left(X_{2}\right)$ and hence the following sequence:

$$
\operatorname{Apr}\left(U^{\prime}\right) \stackrel{f}{\rightarrow} \operatorname{Apr}\left(X_{2}\right) \stackrel{g}{\rightarrow} \operatorname{Apr}\left(U^{\prime \prime}\right)
$$

is rough exact. So, the triple $\left(U^{\prime}, U, U^{\prime \prime}\right)$ is a rough $X_{2}$-sub-exact sequence.

To prove the triple $\left(U^{\prime}, U, U^{\prime \prime}\right)$ is a rough $X_{2}$-sub-exact sequence implies the triple $\left(U^{\prime}, U, U^{\prime \prime}\right)$ is a rough $X_{1}$-sub-exact sequence can be shown in a similar way.

\section{CONCLUSIONS}

The sub-exact sequence of rough groups is a generalization of the exact sequence of rough groups. Furthermore, the union of finite rough groups which the same upper approximation is also a rough group. If $(U, \theta)$ is an approximation space, and $X_{1}, X_{2}$ are rough groups of $U$ such that $\overline{\operatorname{Apr}}\left(X_{1}\right)=\overline{\operatorname{Apr}}\left(X_{2}\right)$, then the triple $\left(U^{\prime}, U, U^{\prime \prime}\right)$ is an $X_{1}$-sub-exact sequence if and only if the triple $\left(U^{\prime}, U, U^{\prime \prime}\right)$ is an $X_{2}$-sub-exact sequence.

\section{ACKNOWLEDGMENTS}

The authors want to thank the reviewers for their insightful suggestions and efforts towards improving our manuscript. Furthermore, the authors wish to thank the Research Institutions and Community Service of Universitas Lampung for this research support and funding under the Research Contract No: 1667/UN 26.21/PN/2021.

\section{AUTHOR CONTRIBUTIONS STATEMENT}

NS is the lead investigator in this study. She collected literature related to sub-exacts and group in algebra. FF and AF help in analyzing the development of theory about the group.

\section{REFERENCES}

Aminizadeh, R., Rasouli, H., \& Tehranian, A. (2018). Quasi-exact sequences of s-acts. Bull.Mallays. Math.Sci.Soc., 42(5), 2225-2235. 
Bagirmaz, N. (2019). Direct products of rough subgroups. Eskişehir Technical University Journal of Science and Technology A - Applied Sciences and Engineering, 20(3), 307316.

Bagirmaz, N., \& Ozcan, A. F. (2015). Rough semigroups on approximation spaces. International Journal of Algebra, 9(7), 339-350.

Biswas, R., \& Nanda, S. (1994). Rough groups and rough subring. Bull. Polish Acad. Sci. Math., $42(3), 251-254$.

Davvaz, B. (2004). Roughness in rings. Information Sciences, 164(4), 147-163.

Davvaz, B., \& Mahdavipour, M. (2006). Roughness in modules. Information Sciences, 176(24), 3658-3674.

Davvaz, B., \& Parnian-Garamaleky, Y. A. (1999). A note on exact sequences. Bulletin of The Malaysian Mathematical Society, 22(1), 53-56.

Elfiyanti, G., D. Nasution, I. M., \& Amartiwi, U. (2016). Abelian property of the category of U-complexes chain of U-complexes. Int. J. Math. Anal., 10(17), 849-853.

Faisol, A., Fitriani, \& Sifriyani. (2021). Determining the noetherian property of generalized power series modules by using X-sub-exact sequence. J. Phys.: Conf. Ser., 1751(1), 012028.

Fitriani, Surodjo, B., \& Wijayanti, I. E. (2016). On sub-exact sequences. Far East Journal of Mathematical Sciences, 100(7), 1055-1065.

Fitriani, Surodjo, B., \& Wijayanti, I. E. (2017). On X-sub-linearly independent modules. Journal of Physics: Conference Series, 893(1), 1-6.

Fitriani, Wijayanti, I. E., \& Surodjo, B. (2018a). A generalization of basis and free modules relatives to a family of R-modules. Journal of Physics: Conference Series, 1097(1), 1-6.

Fitriani, Wijayanti, I. E., \& Surodjo, B. (2018b). Generalization of U-generator and Msubgenerator related to category $\sigma[\mathrm{M}]$. Journal of Mathematics Research, 10(4), 101106.

Li, F., \& Zhang, Z. (2014). The homomorphisms and operations of rough groups. The Scientific World Journal, 2014, 1-6.

Isaac, P., \& Paul, U. (2017). Rough G-modules and their properties. Advances in Fuzzy Mathematics, 12(1), 93-100.

Jesmalar, L. (2017). Homomorphism and isomorphism of rough group. International Journal of Advance Research, Ideas and Innovations in Technology, 3(3), 1382-1387.

Kuroki, N. (1997). Rough ideals in semigroups. Inform. Sci., 100, 139-163.

Miao, D., Han, S., Li, D., \& Sun, L. (2005). Rough group, rough subgroup and their properties. In Lecture Notes in Artificial Intelligence, 3641, 104-113.

Pawlak, Z. (1991). Rough sets-theoretical aspects of reasoning about data. Dordrecht, Kluwer.

Sinha, \& Prakash. (2016). Rough exact sequences of modules. International Journal of Applied Engineering Research, 11(4), 2513-2517. 